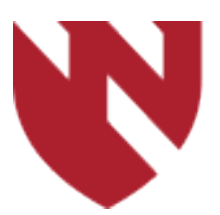

\title{
Risk of Subsequent Atherosclerotic Cardiovascular Disease After the First Unprovoked Venous Thromboembolism in Patients With Rheumatiod Arthritis
}

\author{
Gulsen Ozen \\ University of Nebraska Medical Center \\ Sofia Pedro \\ The National Databank for Rheumatic Diseases \\ Rebecca Schumacher \\ The National Databank for Rheumatic Diseases \\ Teresa A. Simon \\ Physicians Research Center, LLC \\ Kaleb Michaud \\ University of Nebraska Medical Center
}

Tell us how you used this information in this short survey.

Follow this and additional works at: https://digitalcommons.unmc.edu/gmerj

Part of the Higher Education Commons, and the Medicine and Health Sciences Commons

\section{Recommended Citation}

Ozen, G., Pedro, S., Schumacher, R., Simon, T. A., , Michaud, K. Risk of Subsequent Atherosclerotic Cardiovascular Disease After the First Unprovoked Venous Thromboembolism in Patients With Rheumatiod Arthritis. Graduate Medical Education Research Journal. 2020 Sep 29; 2(1). https://digitalcommons.unmc.edu/gmerj/vol2/iss $1 / 51$ 


\section{Risk of Subsequent Atherosclerotic Cardiovascular Disease After the First Unprovoked Venous Thromboembolism in Patients With Rheumatiod Arthritis}

\section{Creative Commons License}

\section{(c) (1) $\Theta(9$}

This work is licensed under a Creative Commons Attribution-Noncommercial-No Derivative Works 4.0 License. 


\section{Catamenial Psychosis: A Forgotten Cause of Psychosis}

Andrew Engle ${ }^{1}$, Steven Embry', Kevin Sisk ${ }^{1}$

${ }^{1}$ University of Nebraska Medical Center, Department of Family Medicine

\section{Mentor: Kevin Sisk}

Program: Family Medicine

Type: Original Research

Background: Catamenial psychosis is a rare subtype of menstrual psychosis which shares clinical features with bipolar disorder. It is characterized by acute, periodic, and remitting psychosis associated with the onset of a woman's menstrual cycle. The pathophysiology, while incompletely understood, is hypothesized to involve the hypothalamic-pituitary-ovarian axis and management includes menstrual suppression. Treatment typically yields prompt and dramatic symptom resolution. Consent was obtained from the patient.
Methods: A 40 year old female presented for evaluation of chronic, cyclical episodes of abnormal mentation with associated visual and auditory hallucinations. She had previously been diagnosed with Bipolar 1 Disorder and despite medical therapy continued to experience episodes psychosis which included auditory hallucinations. However, given her new onset visual hallucinations, she was admitted for further workup.

Results: Neurology and Psychiatric services were consulted and a thorough medical and neurologic workup including brain MRI, lumbar puncture, electrolyte, and infectious studies failed to reveal an organic cause of her symptoms. Further history revealed her recurring symptoms frequently aligned with the initiation of her menstrual cycle, and she had experienced improvement in her symptoms in the past while on OCPs. Due to her recurring, cyclical episodes of psychosis with a temporal relationship to the onset of menstruation, the presumptive diagnosis of catamenial psychosis was made and the patient was referred for menstrual suppression.

Conclusion: Catamenial psychosis is rare, but likely underrecognized. All women of reproductive age with symptoms of psychosis should be screened for a correlation with their menstrual cycle as treatment results in drastic and prompt improvement.

https://doi.org/10.32873/unmc.dc.gmerj.2.1.049

\section{Risk of Subsequent Atherosclerotic Cardiovascular Disease After the First Unprovoked Venous Thromboembolism in Patients With Rheumatoid Arthritis Gulsen Ozen 1 , Sofia Pedro², Rebecca Schumacher ${ }^{2}$, Teresa A. Simon ${ }^{3}$, Kaleb Michaud ${ }^{1,2}$}

${ }^{1}$ University of Nebraska Medical Center, Department of Internal Medicine

${ }^{2}$ FORWARD, The National Databank for Rheumatic Diseases, Wichita, KS

${ }^{3}$ Physicians Research Center LLC, Toms River, NJ

Mentor: Kaleb Michaud

Program: Internal Medicine

Type: Original Research

Objective: To determine the risk of subsequent ASCVD in RA patients with unprovoked first VTE

Methods: RA patients with $\geq 1$-year participation in FORWARD from 1998 through 2018 were assessed for incident nonfatal and fatal ASCVD (myocardial infarction and stroke) validated from hospital/ death records. We excluded patients with prior VTE/ASCVD and active cancer. We identified patients with first unprovoked VTE. We calculated event rates and estimated the risk of subsequent ASCVD in these patients compared to patients with no history of VTE and ASCVD by using Cox proportional hazards with adjustment for sociodemographics, comorbidities, and RA severity measures.

Results: In 25,070 RA patients with no VTE or ASCVD and 506 patients with first unprovoked VTE, we identified 1,283 and 38 first ASCVD events during median (IQR) 4.7 (2.4-8.9) years of follow-up. The incidence rate $(95 \% \mathrm{CI})$ of ASCVD was higher in patients with VTE vs. patients without any CVD (8.68 [8.22-9.17] vs. 23.53
[17.12-32.33] per 10,000 patient-years). After multivariable adjustment, we found that patients with an unprovoked VTE had a

Conclusion: RA patients with unprovoked VTE as the first CVD had twofold risk of ASCVD. RA patients with unprovoked VTE

Table 1.

Crude incidence rates and risk of ASCVD in patients with RA by unprovoked VTE.

\begin{tabular}{lccccc} 
& $\begin{array}{c}\text { Events/ } \\
\text { Patients }\end{array}$ & Patient-years & $\begin{array}{c}\text { Incidence Rate } \\
(95 \% \mathrm{Cl})^{*}\end{array}$ & $\begin{array}{c}\text { Unadjusted } \\
(\mathrm{HR}(95 \% \mathrm{Cl})\end{array}$ & $\begin{array}{c}\text { Adjusted HRl } \\
(95 \% \mathrm{Cl})\end{array}$ \\
\hline $\begin{array}{l}\text { Patients without } \\
\text { VTE or ASCVD }\end{array}$ & $1,283 / 25,070$ & 147,735 & $\begin{array}{c}8.68 \\
(8.22-9.17)\end{array}$ & - & - \\
\hline $\begin{array}{l}\text { Patients with first unprovoked } \\
\text { VTE (no prior ASCVD or VTE) }\end{array}$ & $38 / 506$ & 16,152 & $\begin{array}{c}23.53 \\
(17.12-32.33)\end{array}$ & $\begin{array}{c}2.50 \\
(1.81-3.44)\end{array}$ & $\begin{array}{c}2.05 \\
(1.43-2.95)\end{array}$ \\
\hline DVT only & $21 / 325$ & 11,150 & $\begin{array}{c}18.83 \\
(12.28-28.87)\end{array}$ & $\begin{array}{c}2.03 \\
(1.32-3.12)\end{array}$ & $\begin{array}{c}1.93 \\
(1.22-3.06)\end{array}$ \\
\hline Pulmonary emboli & $17 / 181$ & 5,002 & $\begin{array}{c}33.99 \\
(21.13-54.67)\end{array}$ & $\begin{array}{c}3.78 \\
(2.50-5.70)\end{array}$ & $\begin{array}{c}2.52 \\
(1.57-4.04)\end{array}$ \\
\hline
\end{tabular}

*Per 10,000 patient-years

YAdjusted for age, sex, disease duration, socioeconomic status (annual income, insurance, location of residency), ethnicity, smoking, hypertension , diabetes, comorbidity index, BMI, HAQ, patient global and pain scores, glucocorticoid use DMARDs including MTX, HCQ, TNFi and nonTNFi bDMARDs, NSAIDs, statins, fracture, pulmonary disease, prior count of csDMARDs and bDMARDs, calendar year

significantly increased risk of ASCVD (HR [95\% CI], 2.05 [1.43-2.95]). The risk increase persisted in patients with only DVT (HR [95\% CI], 1.93 [1.22-3.06]) and the risk in patients with PE was even higher (HR [95\% CI], 2.52 [1.57-4.04]) (Table 1). should be evaluated carefully for ASCVD in the presence of concerning symptoms and $\mathrm{CV}$ risk screening and management should be optimized.

https://doi.org/10.32873/unmc.dc.gmerj.2.1.072 